\title{
Conservative Treatment of Primary and Nonsyndromic Odontogenic Keratocyst: An Overview of the Practice
}

\author{
Yuri Slusarenko da Silva* and Maria da Graça Naclério-Homem \\ Faculty of Dentistry, Department of Oral and Maxillofacial Surgery, Traumatology and Prosthesis, \\ University of São Paulo, Brazil
}

*Corresponding author: Yuri Slusarenko da Silva, Faculty of Dentistry, Department of Oral and Maxillofacial Surgery, Traumatology and Prosthesis, University of São Paulo, Av Prof. Lineu Prestes 2227 Butantã-São Paulo, ZIP Code: 05508000, Brazil, Tel: +55-11-30917832/+55-11-95249-6124

\begin{abstract}
Background: Odontogenic Keratocyst (OKC) is a locally aggressive odontogenic cyst with a high recurrence rate after treatment. Several conservative surgeries have been suggested in the treatment of Keratocysts but working with an overview of the practice may render better outcomes.

Methods: We conducted a literature review in the databases MEDLINE, Web of Science, Scopus, Cochrane Library and Google Scholar as well as in the gray literature (books and thesis) for studies reporting on the pathogenesis, clinical presentation, imaging, diagnosis and treatment modalities of OKC's.

Results: Features of OKC's are discussed in light of literature in order to establish the best protocol in the diagnosis, treatment planning and treatment itself.

Conclusions: OKC's deserve special attention over other regular, ordinary, odontogenic cysts. Radiographs and CTscans in the assessment of OKC's, preoperative histological diagnosis and enucleation of OKC's followed by the application of Carnoy's and excision of the overlying mucosa in the region of attachment of the oral mucosa to the cyst is usually an appropriate protocol in the treatment of the OKC.
\end{abstract}

\section{Keywords}

Odontogenic keratocyst, Keratocystic odontogenic tumor, Odontogenic cysts, Carnoy's solution, Therapy, Recurrence

\section{Introduction}

The latest World Health Organization classification of Tumours of the Head and Neck (2017) reevaluated the concepts on the clinical, radiological and biological features of the Keratocystic Odontogenic Tumor (KCOT) and has decided to rename this lesion to Odontogenic Keratocyst again (OKC) [1]. The motivation for this policy change, however, is lacking. The OKC is potentially a very aggressive lesion (Figure 1 ) and this name change may bring about some confusion among surgeons and tends to lessen the alertness among surgeons to treat this lesion adequately [2].

Apart from its high recurrence rate after treatment [3], Emerson, et al. described the extension of two recurrent OKC's in the mediastinum, via the neck [4]. Other authors have already reported the extension of three OKC's into the base of the skull [5-7], two OKC's penetrating into the temporalis muscle $[8,9]$ and two OKC's into the masseter muscle $[10,11]$. Four case reports have been published showing recurrent OKC's in a bone graft [12-15]. Regular, ordinary, odontogenic cysts do not behave this way [2].

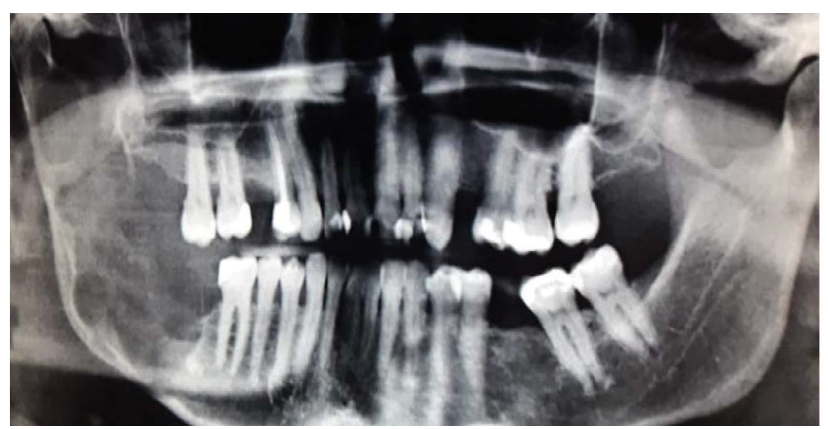

Figure 1: Large OKC in the right posterior region of the mandible demonstrating its aggressiveness.

Citation: Slusarenko da Silva Y, Naclério-Homem MG (2018) Conservative Treatment of Primary and Nonsyndromic Odontogenic Keratocyst: An Overview of the Practice. Int J Oral Dent Health 4:070. doi.org/10.23937/2469-5734/1510070

Accepted: November 14, 2018: Published: November 16, 2018

Copyright: (C) 2018 Slusarenko da Silva Y, Naclério-Homem MG. This is an open-access article distributed under the terms of the Creative Commons Attribution License, which permits unrestricted use, distribution, and reproduction in any medium, provided the original author and source are credited. 
The aggressiveness of the OKC may be attributed to the high mitotic index of the epithelial cyst lining as compared to regular odontogenic cysts [16]. This would explain the recurring OKC after piecemeal enucleation of the cyst, while some of the cyst wall has been left behind. Even though OKC's are thought to be derived from remnants of the dental lamina, the epithelial cell nests and microcysts, often located in the oral mucosa overlying the alveolar ridges may also be an important source of primary and recurrent OKC's [17-19]. This is particularly the case in the posterior region of the jaws.

These epithelial cell nests and/or microcysts are derived from the basal layer of the oral mucosa and can be considered to be hamartias. Histologically, a dropping off phenomenon can be seen in some cases [3,17-20]. In cases of intraosseous OKC's arising from the basal layer of the oral mucosa [21,22], a bone perforation can easily be detected on computed tomography (CT-scans) and such area of the oral mucosa will be attached to the OKC.

The above-mentioned theories about the origin of OKC's and their possible recurrence pattern should play a role in the surgical treatment planning. Several, mainly conservative approaches have been suggested to the OKC's [23-25] like enucleation alone, enucleation followed by adjunctive therapy (application of Carnoy's solution, cryotherapy, peripheral ostectomy), enucleation with or without adjunctive therapy including removal of the overlying mucosa, marsupialization alone and marsupialization followed by delayed enucleation.

In general, treatment modalities of syndromic OKC's (Nevoid Basal Cell Carcinoma Syndrome) are the same of nonsyndromic OKC's. However, the pattern of OKC development in syndromic patients is widely influenced by molecular/genetic alterations such as the inactivation of the PTCH1, a tumor suppressor gene, what explains one of the reasons why syndromic patients often have multiple OKC's in the jawbones. Thus, a recurrent OKC could be, actually, a new, primary OKC $[1,20]$.

It is the aim of the present study is to give a clinical insight and discuss, in light of literature, the main features and modalities of treatment of the nonsyndromic OKC.

\section{Material and Methods}

We conducted a literature review in the databases MEDLINE, Web of Science, Scopus, Cochrane Library and Google Scholar as well as in the gray literature (books and thesis), searching for studies about KCOT or OKC written in English or Portuguese. Only data regarding pathogenesis, clinical presentation, imaging, diagnosis and treatment modalities of OKC's were extracted from the retrieved studies to come up with reliable data to base upon a rational treatment policy.

\section{Results and Discussions}

\section{Pathogenesis of OKC's}

OKC's arise from the proliferation of remnants or off-

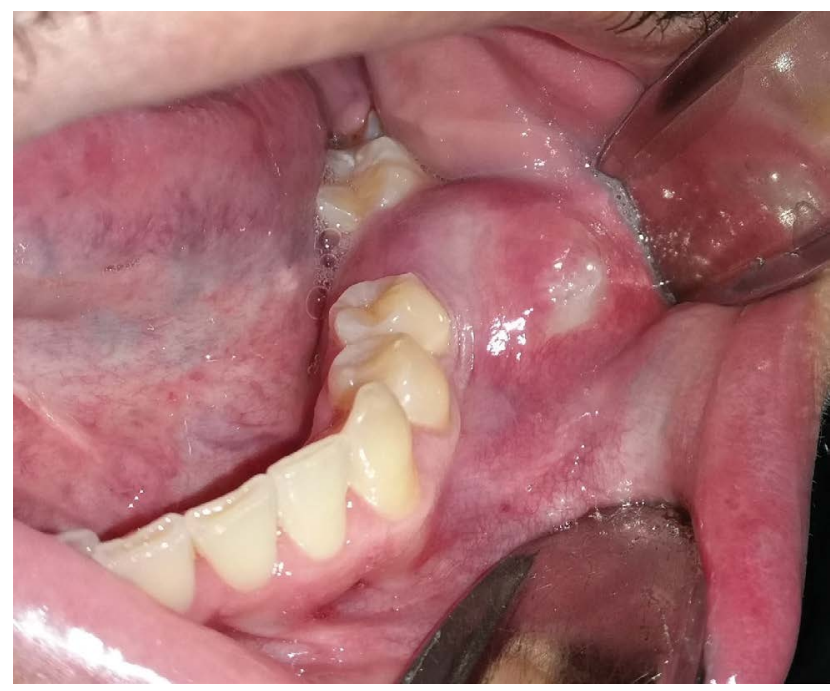

Figure 2: Infected OKC causing pain and swelling in the region of missing tooth 36 .

shoots of the dental lamina as an intraosseous lesion associated or not with an unerupted tooth, mainly in the tooth bearing area (i.e., incisors, canines, premolars and $1^{\text {st }} / 2^{\text {nd }}$ molars area). They may also arise from epithelial cell nests and microcysts, often located in the basal layer of the oral mucosa, mainly in the posterior region of the jaws (i.e., $3^{\text {rd }}$ molar, angle and ramus in the mandible and $3^{\text {rd }}$ molar/maxillary tuberosity in the maxilla) [17-19]. Nonsyndromic OKC's may also suffer a mutation or inactivation of the PTCH1 gene, which activates the SHH signaling pathway and results in the exacerbated proliferation of the cystic epithelium [1,3]. OKC is a potentially a very aggressive and the consensus of being a tumor or a cyst has not been reached yet $[1,2,26]$.

\section{Clinical presentation of OKC's}

OKC's grow in the medullary space of the mandible or maxilla with no or little expansion of the cortical bone $[1,3]$. Thus, initial, small lesions are usually asymptomatic unless they get infected [18]. However, if the cyst perforates thinner regions of the cortical bone, from the inside to the outside, a local swelling may take place (Figure 2). This happens often with regular, ordinary, odontogenic cysts, e.g. radicular or dentigerous cyst. Suddenly, patients may develop trismus in case of larger OKC's in the mandibular ramus (Figure 1). Larger OKC's in the maxilla may expand into the maxillary sinus (Figure 3) and cause nasal obstruction on the same side. On the other hand, slow growing cysts may stimulate periosteal bone apposition and cause bone expansion without cortical perforation. OKC's occur over a wide patient age range, most commonly in the posterior region of the mandible of men in the second to third decades of life [26].

\section{Imaging of OKC's}

Radiographs of OKC's commonly present as unilocular cystic lesion with a well-defined border with or without scalloped margins but may also be multilocular. Fre- 


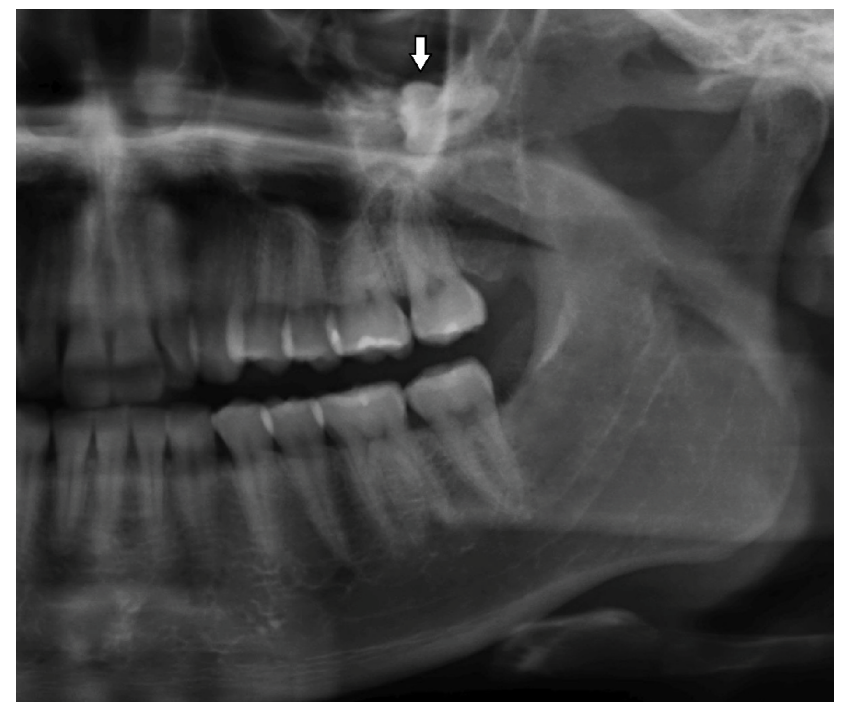

Figure 3: Large OKC in the left maxillary sinus, displacing the tooth 28 superiorly (arrow).

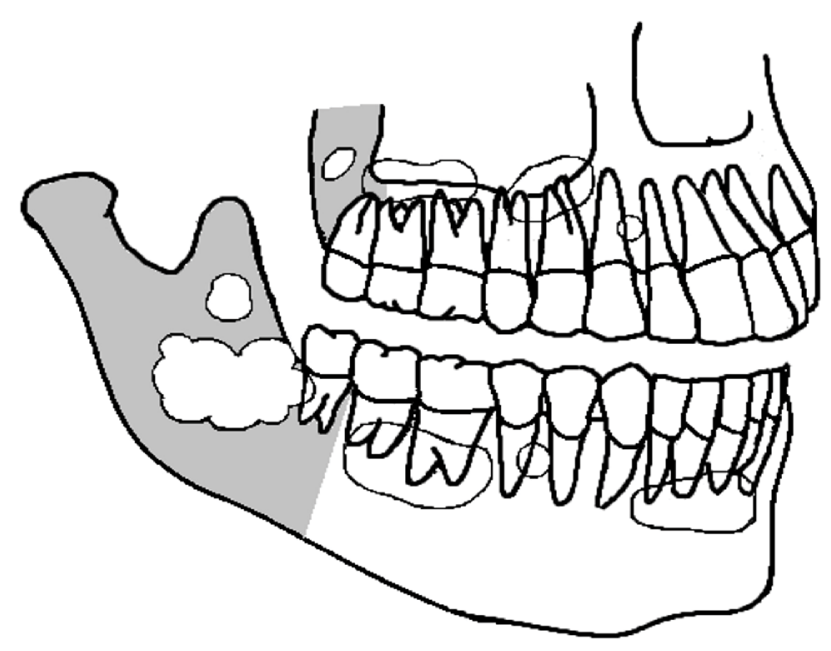

Figure 4: Some of the several possibilities of OKC's presentation in the mandible and maxilla (schematic drawing). They are usually confounded with regular odontogenic cysts. Gray area is the posterior region of the jawbones.

quently, they are not easily distinguishable from regular odontogenic cysts (Figure 4). OKC's may have no relation with a tooth or the crown may be completely inside the cyst. They may be positioned adjacent to the lateral aspect of the tooth root similar to a lateral periodontal cyst [18]. In a review of the radiographic aspects of 1138 OKC's, reported in several studies, including recurrent and syndromic OKC's, we found that 672 were unilocular (59\%), 342 multilocular (30\%), 202 had a smooth or well-defined border (18\%), while 70 had a scalloped border (6\%) [18,27-45]. In many instances, the radiological aspect was not reported.

Computed tomography is a valuable tool in detecting all dimensions of the OKC with a better definition of anatomical structures such as the inferior alveolar nerve (IAN), maxillary sinus, nasal cavity etc. CT-scans allow the precise detection of the cortical perforation (especially in the angle/ramus of the mandible or in the maxillary tuberosity), if present. The cortical perforation is probably

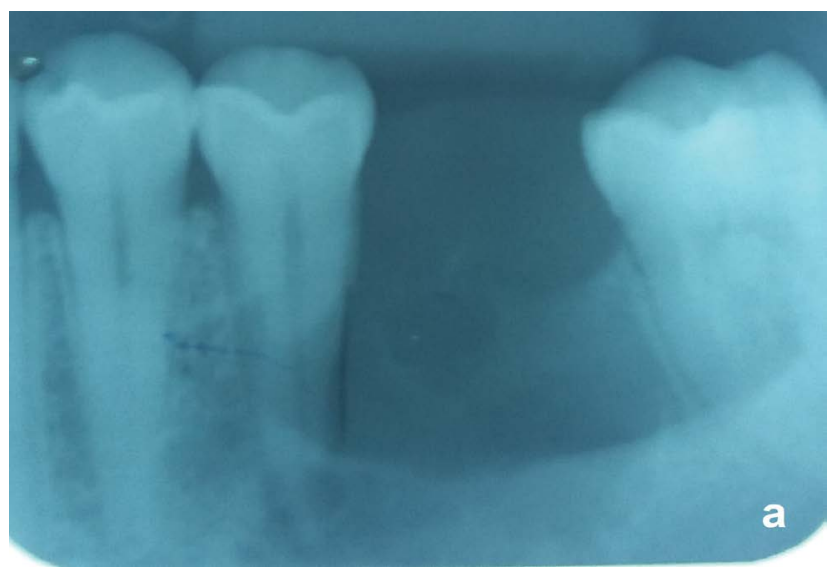

Figure 5a: Same case of the figure 2. Unilocular OKC with a well-defined border between the nonvital tooth 35 and the vital tooth 37 . Observe that the periodontal ligament of both teeth are preserved.

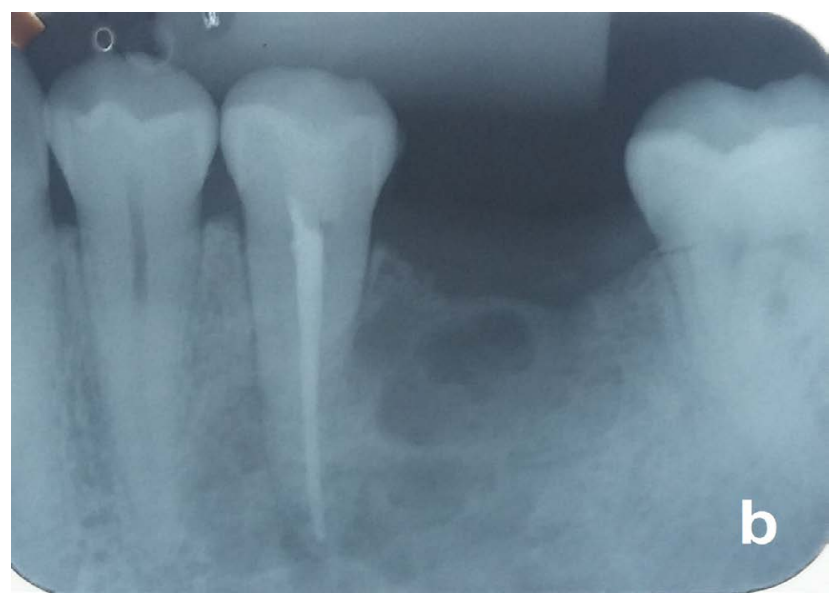

Figure 5b: Tooth 35 was endodontically treated before the surgery.

the area where the overlying oral mucosa is attached to the OKC and such region must be included in the surgical excision. Smaller unilocular cysts, especially in the tooth bearing area, may be easily confounded with regular odontogenic cysts, specially the periodontal lateral cyst.

In the clinical practice, Magnetic Resonance Imaging (MRI) has a limited value but may complement the radiological assessment, particularly in cases of soft tissue involvement of larger OKC's. MRI also helps differentiating OKC's from ameloblastomas and other cysts and tumors of the jaws. MRI detects the presence of locularities and solid masses. It will also shows the thickness of the cyst wall and the content of the cyst by the signal intensity of the intraluminal fluid. We pooled the imaging data of contrast-enhanced MRI of $39 \mathrm{OKC}^{\prime}$ s reported in two studies studies $[46,47]$ and found that 24 were unilocular (62\%) and 15 were multilocular (38\%). The thickness of the cyst wall was thin in 26 OKC's (67\%) and thick in 11 (28\%). However, the information of the capsule thickness of 2 cysts was not available [46]. Regarding the signal intensity of the fluid, 21 OKC's were cystic (54\%). Thirteen were mixed (33\%), i.e. solid and cystic, and 5 were solid (13\%). The solid content, how- 
ever, should be attributed to the deposition of keratinized debris within the cyst and not to the intraluminal proliferation of the cyst wall [46]. The signal intensity of the intraluminal fluid (mainly in non-solid lesions) was predominantly heterogenous (30 OKC's-77\%) rather than homogeneous ( $9 \mathrm{OKC}^{\prime} \mathrm{s}-23 \%$ ), this feature being of particularly interest in distinguishing $\mathrm{OKC}^{\prime} \mathrm{s}$ from ameloblastomas.

\section{Diagnosis of OKC's}

Histopathological assessment by means of an incisional biopsy is the best way to diagnose the OKC before the surgery, when suspicion had arisen from the clinical and radiographic presentation [18]. Incisional biopsy may cause inflammation to the OKC and interfere in the histopathological analysis of the post-surgical specimen, though. The cyst wall is fibrous and lined by a folded, thin, regular parakeratinized epithelium 5-8 cell layers thick, without rete ridges. The parakeratin surface is typically corrugated, and the basal layer is well defined and often palisaded, with hyperchromatic nuclei and focal areas showing reversed nuclear polarity $[1,3,26]$ However, as mentioned before, inflammation of the cyst may render a false-negative result secondary to the metaplasia of the cyst wall. The features of the parakeratinized epithelium and basal layer may have completely disappeared $[48,49]$.

Aspiration biopsies to the study of protein levels and keratin flakes in the aspiration fluid may aid in the diagnosis and help to overcome problems with histopathological results [50].

\section{Treatment modalities}

Overall recommendation: Nonvital teeth close to the OKC may be endodontically treated and maintained (Figure $5 \mathrm{a}$ and Figure $5 \mathrm{~b}$ ) but those with the cyst adhered on the radicular surface or with radicular resorption by the OKC should be removed. After total removal of the OKC, patients should receive a yearly radiological follow-up the first five years and beyond that every two years. Recurrences may occur over as long a period of 25 years [18].

Enucleation of OKC's: Enucleation consists in the total removal of the cyst in one piece, but this task is quite difficult to achieve because of the fragile wall of OKC's. Thus, additional curettage of the bony cavity to remove cyst fragments is frequently necessary. Cyst lining that are left behind in the bony cavity after enucleation or curettage increase the risk of recurrence $[23,24]$. Therefore, if the OKC was diagnosed before the surgery, enucleation alone is discouraged.

No further treatment is required to small OKC's (approximately $1 \mathrm{~cm}$ in diameter or less, commonly in the tooth bearing area) that were diagnosed after enucleation, but patients should have a rigorous radiological follow-up. Recurrences in these areas can be easily dealt without much harm to the patient.
Excision of the overlying mucosa: If CT-scans show cortical perforation, the overlying oral mucosa and its attachment to the OKC should always be excised with a safety margin in order to remove epithelial cell nests and/or microcysts located in this region $[18,21,22]$.

Enucleation of OKC's followed by the application of Carnoy's Solution (CS): Application of CS is probably the best option of adjunctive therapy and the most effective conservative treatment in reducing the recurrence rate of OKC's $[23,24,51]$. It is a safe and low-cost procedure [52]. This solution is composed by $60 \%$ of absolute alcohol, $30 \%$ of chloroform, $10 \%$ of glacial acetic and 1 gram of ferric chloride. CS causes immediate fixation/ inactivation of possible remaining epithelial cells left behind after enucleation and also inactivates epithelial cell nests or microcysts located in areas of cortical perforation, if present. A piece of gauze soaked with CS is applied on the bone cavity with a curved Kelly clamp [18] for 1 minute [50]. Avoid applying CS on the IAN, periodontium of the neighboring vital tooth and thin bony walls of the sinus because of possible irreparable damage to these structures.

Despite the beneficial results of Carnoy's Solution (CS) in reducing the recurrence rate of odontogenic keratocysts, lack of histological information regarding its hypothetically detrimental effects on structures exposed in the operatory field like bone necrosis and poor quality of bone neoformation has led many surgeons to question and abandon this modality of complementary treatment.

Enucleation of OKC's followed by peripheral ostectomy: Peripheral ostectomy may be the second better option of adjunctive therapy in the control of recurrence rate of OKC's. It is a safe and low-cost procedure, showing good results in reducing the recurrence rate $[23,24]$ by the mechanical removal of remaining epithelial cells and epithelial cell nests/microcysts. With a large round bur, remove the osseous tissue up to a depth of $1.5 \mathrm{~mm}$ along the bone cavity, under copious saline irrigation.

Enucleation of OKC's followed by cryotherapy: After enucleation, the spray of liquid nitrogen $\left(-196.6^{\circ} \mathrm{C}\right)$ is applied once on the bone cavity for 1 minute, freezing remaining epithelial cells and epithelial cell nests/microcysts what causes a physical death of the pathologic cells up to a depth of $1.5 \mathrm{~mm}$. However, the use of this technique in reducing the recurrence rate is controversial $[23,24,51]$. Applying the spray of liquid nitrogen on fragile mandibles increases the risk of postoperative pathological fracture.

Marsupialization alone and marsupialization and delayed enucleation: Marsupialization is the conversion of the OKC into an integrant cavity of the oral cavity. It can be definitive (marsupialization alone) or temporary (marsupialization and delayed enucleation). When the cyst is exposed to the oral milieu, the epithelial 
cyst lining will undergo metaplasia to become indistinguishable from the epithelium of the oral mucosa [17] while the cystic cavity reduces in size, due to the decompression, which can be monitored on radiographs or CT cans. OKC's become less aggressive after metaplasia but still have a high recurrence rate $[23,24,51]$. On the other hand, marsupialization for approximately 12 to 18 months and delayed enucleation demonstrates a better outcome regarding recurrence rate [25] provided the marsupialized fragment is removed at the region of cortical perforation, if present (Paul JW Stoelinga, Emeritus Professor of Radboud University, personal communication. See section "excision of the overlying mucosa"). Marsupialization may be somewhat cumbersome for the patient. Therefore, it is more indicated in elderly people or poor risk patients with large-sized OKC's.

\section{Final Considerations}

Odontogenic Keratocysts deserve special attention over other regular, ordinary odontogenic cysts concerning the diagnosis, treatment planning and treatment itself. Despite the current change in the name of this lesion, OKC's may behave as a tumor and bring some confusion to the clinical practice.

In short, radiographs and CT-scans are usually enough in the assessment of OKC's. We recommend that suspect lesions have a histological diagnosis before the decision of what definitive treatment will be followed. In healthy patients, enucleation of OKC's followed by the application of Carnoy's and excision of the overlying mucosa in the region of attachment to the OKC should be the treatment of choice. In cases of large OKC's, mainly in the posterior region of the jaws, marsupialization for 12-18 months before the definitive treatment is a good option in reducing the size of the lesion to decrase the risk of the surgical procedure.

Eventually, the overview of the practice of OKC's may be applied to the treatment of other aggressive odontogenic lesions such as the solid/multicystic ameloblastoma.

\section{Acknowledgements}

The authors declare that they have no conflict of interest.

\section{References}

1. Speight $P$, Devilliers $P$, Li TJ, Odell EW, Wright JM (2017) Odontogenic keratocyst. In: El-Naggar AK, Chan JKC, Grandis JR, Takata T, Slootweg PJ, WHO classification of head and neck tumours. ( $4^{\text {th }}$ edn), IARC, Lyon, France, 235-236.

2. Stoelinga PJW (2018) Keratocystic odontogenic tumour (KCOT) has again been renamed odontogenic keratocyst (OKC). Int J Oral Maxillofac Surg 30313-30318.

3. Shear M, Speight PM (2007) Odontogenic keratocyst. In: Shear M, Speight PM, Cysts of the oral and maxillofacial regions. ( $4^{\text {th }}$ edn), Blackwell Publishing Ltd, 6-58.
4. Emerson TG, Whitlock RI, Jones JH (1972) Involvement of soft tissue by odontogenic keratocysts (primordial cysts). $\mathrm{Br}$ J Oral Surg 9: 181-185.

5. Jackson IT, Potparic Z, Fasching M, Schievink WI, Tidstrom $\mathrm{K}$, et al. (1993) Penetration of the skull base by dissecting keratocyst. J Craniomaxillofac Surg 21: 319-325.

6. Franc C, Cresseaux P, Richard L, Breton P, Freidel M (1996) The keratocyst or epidermoid cyst: The current state of understanding apropos of a case with intracranial involvement. Rev Stomatol Chir Maxillofac 97: 270-282.

7. Soost F, Stoll C, Gerhardt O, Neumann HJ (1999) Keratocysts of the jaws with an expansion to the skull base. Zentralbl Neurochir 60: 11-14.

8. Worral SF (1992) Recurrent odontogenic keratocyst within the temporalis muscle. Br J Oral Surg 30: 59-62.

9. Abé T, Maruyama S, Yamazaki M, Essa A, Babkair H, et al. (2014) Intramuscular keratocyst as a soft tissue counterpart of keratocystic odontogenic tumor: Differential diagnosis by immunohistochemistry. Hum Pathol 45: 110-118.

10. Makarla S, Bavle RM, Muniswamappa S, Narasimhamurthy S (2015) A large extragnathic keratocystic odontogenic tumour. Case Rep Pathol 2015.

11. Yamamoto K, Matsusue $Y$, Kurihara M, Takahashi $Y$, Kirita T (2013) A keratocyst in the buccal mucosa with the features of keratocystic odontogenic tumor. Open Dent J 7: 152-156.

12. Schofield JJ (1971) Unusual recurrence of odontogenic keratocyst. Br Dent J 130: 487-489.

13. Persson G (1973) Remarkable recurrence of a keratocyst in a bone-graft. Int J Oral Surg 2: 69-76.

14. Attenborough NR (1974) Recurrence of an odontogenic keratocyst in a bone graft: Report of a case. Br J Oral Surg 12: 33-39.

15. DeGould MD, Goldberg JS (1991) Recurrence of an odontogenic keratocyst in a bone graft. Report of a case. Int $J$ Oral Maxillofac Surg 20: 9-11.

16. Toller $P$ (1967) Origin and growth of cysts of the jaws. Ann R Coll Surg Engl 40: 306-336.

17. Stoelinga PJW, Peters JH (1973) A note on the origin of keratocysts of the jaws. Int J Oral Surg 2: 37-44.

18. Stoelinga PJ (2001) Long-term follow-up on keratocysts treated according to a defined protocol. Int J Oral Maxillofac Surg 30: 14-25.

19. Stoelinga PJW (2003) Etiology and pathogenesis of keratocysts. Oral Maxillofac Surg Clin North Am 15: 317-324.

20. Stoelinga PJW, Peters JH, van de Staak WJ, Cohen MM Jr (1973) Some new findings in the basal-cell nevus syndrome. Oral Surg Oral Med Oral Pathol 36: 686-692.

21. Stoelinga PJ (2003) Excision of the overlying, attached mucosa, in conjunction with cyst enucleation and treatment of the bony defect with carnoy solution. Oral Maxillofac Surg Clin North Am 15: 407-414.

22. Al-Moraissi EA, Pogrel MA, Ellis E (2016) Does the excision of overlying oral mucosa reduce the recurrence rate in the treatment of the keratocystic odontogenic tumor? A systematic review and meta-analysis. J Oral Maxillofac Surg 74: 1974-1982.

23. Blanas N, Freund B, Schwartz M, Furst IM (2000) Systematic review of the treatment and prognosis of the odontogenic keratocyst. Oral Surg Oral Med Oral Pathol Oral Radiol Endod 90: 553-558. 
24. Al-Moraissi EA, Dahan AA, Alwadeai MS, Oginni FO, Al-Jamali JM, et al. (2017) What surgical treatment has the lowest recurrence rate following the management of keratocystic odontogenic tumor? A large systematic review and meta-analysis. J Craniomaxillofac Surg 45: 131-144.

25. de Castro MS, Caixeta CA, de Carli ML, Ribeiro Júnior NV, Miyazawa M, et al. (2018) Conservative surgical treatments for nonsyndromic odontogenic keratocysts: A systematic review and meta-analysis. Clin Oral Investig 22: 2089-2101.

26. Philipsen HP (2005) Keratocystic odontogenic tumour. In: Barnes L, Eveson JW, Reichart P, Sidransky, World Health Organization Classification of Tumours. Pathology and Genetics of Head and Neck Tumours, IARC Press, Lyon, France, 306-307.

27. Ribeiro Junior O, Borba AM, Alves C, De Gouveia M, Coracin FL, et al. (2018) Keratocystic odontogenic tumors and carnoy's solution: Results and complications assessment. Oral Dis 18: 548-557.

28. Vedtofte P, Praetorius F (1979) Recurrence of the odontogenic keratocyst in relation to clinical and histological features. A 20-year follow-up study of 72 patients. Int J Oral Surg 8: 412-420.

29. Bataineh AB, al Qudah M (1998) Treatment of mandibular odontogenic keratocysts. Oral Surg Oral Med Oral Pathol Oral Radiol Endod 86: 42-47.

30. Berge TI, Helland SB, Sælen A, Øren M, Johannessen AC et al. (2016) Pattern of recurrence of nonsyndromic keratocystic odontogenic tumors. Oral Surg Oral Med Oral Pathol Oral Radiol 122: 10-16.

31. Boffano P, Ruga E, Gallesio C (2010) Keratocystic odontogenic tumor (odontogenic keratocyst): Preliminary retrospective review of epidemiologic, clinical, and radiologic features of 261 lesions from University of Turin. J Oral Maxillofac Surg 68: 2994-2999.

32. Deepthi PV, Beena VT, Padmakumar SK, Rajeev R, Sivakumar R (2016) A study of 1177 odontogenic lesions in a South Kerala population. J Oral Maxillofac Pathol 20: 202207.

33. Leung YY, Lau SL, Tsoi KY, Ma HL, Ng CL (2016) Results of the treatment of keratocystic odontogenic tumours using enucleation and treatment of the residual bony defect with Carnoy's solution. Int J Oral Maxillofac Surg 45: 1154-1158.

34. MacDonald D, Gu Y, Zhang L, Poh C (2013) Can clinical and radiological features predict recurrence in solitary keratocystic odontogenic tumors? Oral Surg Oral Med Oral Pathol Oral Radiol 115: 263-271.

35. Mamabolo M, Noffke C, Raubenheimer E (2011) Odontogenic tumours manifesting in the first two decades of life in a rural African population sample: A 26 year retrospective analysis. Dentomaxillofac Radiol 40: 331-337.

36. Mclvor J (1972) The radiological features of odontogenic keratocysts. Br J Oral Surg 10: 116-125.

37. Ong ST, Siar CH (1995) Odontogenic keratocysts in a malaysian population: Clinical, radiological and histological considerations. Annals Dent 2: 9-14.
38. Park TW, Kim SR (1985) Clinical and radiographic study of odontogenic keratocyst. Oral Radiol 1: 43-53.

39. Simiyu BN, Butt F, Dimba EA, Wagaiyu EG, Awange DO, et al. (2013) Keratocystic odontogenic tumours of the jaws and associated pathologies: A 10 year clinicopathologic audit in a referral teaching hospital in Kenya. J Craniomaxillofac Surg 41: 230-234.

40. Tabrizi R, Omidi M, Dehbozorgi M, Hekmat M (2014) Correlation of radiographic features and treatments with the frequency of recurrence in odontogenic keratocysts of the mandible. J Craniofac Surg 25: e413-e417.

41. Urs AB, Arora S, Singh H (2014) Intra-osseous jaw lesions in paediatric patients: A retrospective study. J Clin Diagn Res 8: 216-220.

42. Brondum N, Jensen VJ (1991) Recurrence of keratocysts and decompression treatment. A long-term follow-up of forty-four cases. Oral Surg Oral Med Oral Pathol 72: 265-269.

43. Nakamura N, Mitsuyasu T, Mitsuyasu $\mathrm{Y}$, Taketomi T, Higuchi $Y$, et al. (2002) Marsupialization for odontogenic keratocysts: Long-term follow-up analysis of the effects and changes in growth characteristics. Oral Surg Oral Med Oral Pathol Oral Radiol Endod 94: 543-553.

44. Cunha JF, Gomes CC, De Mesquita RA, Goulart EMA, De Castro WH, et al. (2016) Clinicopathologic features associated with recurrence of the odontogenic keratocyst: A cohort retrospective analysis. Oral Surg Oral Med Oral Pathol Oral Radiol 121: 629-635.

45. Irvine GH, Bowerman JE (1985) Mandibular keratocysts: Surgical management. Br J Oral Maxillofac Surg 23: 204209.

46. Minami $\mathrm{M}$, Kaneda $\mathrm{T}$, Ozawa $\mathrm{K}$, Yamamoto $\mathrm{H}$, Itai $\mathrm{Y}$, et al. (1996) Cystic lesions of the maxillomandibular region: MR imaging distinction of odontogenic keratocysts and ameloblastomas from other cysts. AJR Am J Roentgenol 166: 943-949.

47. Probst FA, Probst M, Pautke Ch, Kaltsi E, Otto S, et al. (2015) Magnetic resonance imaging: A useful tool to distinguish between keratocystic odontogenic tumours and odontogenic cysts. Br J Oral Maxillofac Surg 53: 217-222.

48. Rodu B, Tate AL, Martinez MG (1987) The implications of inflammations in odontogenic keratocysts. J Oral Pathol 16: 518-521.

49. Haring JI, van Dis ML (1988) Odontogenic keratocysts: A clinical, radiographic and histological study. Oral Surg Oral Med Oral Pathol 66: 145-153.

50. Voorsmit RACA (1984) The incredible keratocyst [thesis]. University of Nijmegen.

51. Johnson NR, Batstone MD, Savage NW (2013) Management and recurrence of keratocystic odontogenic tumor: A systematic review. Oral Surg Oral Med Oral Pathol Oral Radiol 116: 271-276.

52. Slusarenko da Silva Y (2016) Análise histológica dos efeitos da solução de carnoy em defeitos monocorticais realizados na mandíbula de ratos wistar [thesis]. University of São Paulo.

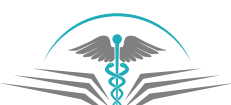

